\title{
Case-control study of breast cancer in south east England: nutritional factors
}

\author{
J Cade, E Thomas, A Vail
}

\begin{abstract}
Objectives-To explore dietary risk factors, in particular fat intake, for breast cancer, using an approach to reduce recall bias of subjects and so provide a more reliable estimate of dietary intake than previous similar studies.

Design-A case-control study of women aged 50-65 years attending the breast assessment clinics of the breast screening programme in Southampton and Portsmouth, southern England. Data were analysed for all women requiring further clinical procedures; all women recalled to have an early rescreen; and a random sample of women found to be normal and referred for a routine rescreening appointment (standard recall).

Measurements-An interview obtained information on various lifestyle characteristics including smoking and alcohol intake, weight, waist, and hip measurements were also taken at the clinic. Women were given a detailed questionnaire on food intake to complete at home and return by post.
\end{abstract}

Results-1577 women were included in the study: 220 with breast cancer (cases); 179 with benign breast disease; 353 early rescreen and 825 given a standard recall appointment. There were few differences in nutritional intake between the four groups. Logistic regression analyses were carried out comparing the dietary intake of cases with that of each control group adjusting for important demographic and reproductive factors. Results for the case and standard recall comparison are presented. The only non-calorific nutrient to reach significance was iron, which was negatively associated with risk $(p=0.03)$. For fat intake, the odds decreased with increasing polyunsaturated fat $(p=0.15)$, showed no trend with monounsaturated fat $(p=0.37)$ and increased $(p=0.10)$ with increasing saturated fat. No pattern was clear for the other calorie providing nutrients.

Conclusions-In line with recent cohort studies, this study has shown no evidence to support the hypothesis that dietary fat is an important contributor to breast cancer rates. Biases should have been reduced by studying subjects from the screening programme who were at an early stage of disease.

(F Epidemiol Community Health 1998;52:105-110)
The aetiology of breast cancer is uncertain. Various risk factors have been postulated. ${ }^{1}$ Diet has been prominent among the hypothesised environmental risk factors but few, if any, constituents of the diet can definitely be associated with the disease. Most risk factors are associated with only a modest increase in risk. The American Cancer Society has estimated that only about one quarter of breast cancer cases can be accounted for by known risk factors. ${ }^{2}$ It is important to discover if diet is involved in the aetiology of breast cancer, as it is more amenable to change than some other risk factors (for example, age at menarche).

Dietary fat has long been suspected of playing a part in the aetiology of breast cancer. Animal experiments in the early 1940 s showed a positive relation between a high fat diet and risk of mammary gland cancer. ${ }^{3}$ A metaanalysis of animal experiments has shown that not only is total fat consumption a risk factor but also type of fat is important, linoleic acid (a polyunsaturated fat) and lard (a saturated fat) may increase risk, whereas fish oil (also a polyunsaturated fat) may be protective. ${ }^{4}$

Ecological studies have shown a positive relation between a high fat diet and risk of breast cancer mortality: both between countries and over time in the same country..$^{5-7}$ However, the findings of these studies are limited. Average per capita consumption data take no account of individual differences in dietary practices and there may be other factors related to fat intake that are the real cause of the high correlations. Migrant studies have shown an increase in breast cancer rates with increasing fat intake.

Case-control studies relevant to fat and breast cancer have reported conflicting results. A review of 35 case-control studies showed increasing risk in association with high meat consumption in 12 studies. Fourteen of the studies presented odds ratios for total fat intake. Most of the studies suggested an increase in risk of breast cancer with higher fat consumption, but only two had confidence intervals excluding unity. ${ }^{9}$ One study suggested a protective effect of a higher fat diet. ${ }^{10} \mathrm{~A}$ metaanalysis of 12 case-control studies showed a statistically significant increased risk of breast cancer in women who consumed more fat, primarily because of intake of saturated and monounsaturated fats, rather than polyunsaturated fat. ${ }^{11} \mathrm{~A}$ disadvantage of case-control studies is that misclassification may arise because of bias in selection of patients and bias in recall of past diet. Recall of usual pre-disease intake is influenced by current, different 
diet, ${ }^{12}{ }^{13}$ and possibly also by knowledge of highly publicised hypotheses.

Cohort studies are not subject to the same recall and selection biases because dietary intake data are collected before the onset of disease. A review of 17 cohort studies $^{9}$ showed that for all except one poorly designed study there was no increased risk of breast cancer associated with higher consumption of either total or saturated fat. It may be that within any cultural group the range of fat intakes is too narrow to observe an effect. ${ }^{14}$ However, a pooled analysis of seven cohort studies found no evidence of a positive association between total fat and breast cancer. Even among those with energy intake from fat less than 20 per cent of total energy intake there was no reduction in risk. ${ }^{15}$ Differences in results between the cohort studies and case-control studies may result from methodological biases.

The role of other nutrients and breast cancer risk has also been explored, in particular, antioxidant vitamins, fibre, and alcohol. Vitamin A (in particular $\beta$ carotene) and vitamin $C$ are markers of fruit and vegetable intake. Available data support a modest protective effect of vitamin A. ${ }^{11}{ }^{16}{ }^{17}$ Vitamin C has been shown to be protective in some, ${ }^{11}$ but not all studies. ${ }^{18}$ Perhaps because less is known about micronutrients by the general population recall bias has not been demonstrated for these nutrients in a case-control study. ${ }^{19}$ Dietary fibre has been suggested to be protective against breast cancer, although the effect may be small. ${ }^{20}$ Total energy intake has also been implicated through promotion of growth in height and weight. Postmenopausal women show an increase in risk with increasing height and weight. There seems to be an inverse association of breast cancer risk with body mass index premenopausally.

Our aim was to explore dietary risk factors for breast cancer in a case-control study. The approach used methods to reduce recall bias of the subjects and thus provide more reliable estimates of dietary intake than previous casecontrol studies.

\section{Methods}

Details of the screening programme and sampling procedure have been described previously. ${ }^{21}$ In summary, women aged 50-65 years, who attended the breast assessment clinics of the breast screening programme in Southampton and Portsmouth (in southern England) over two years (1990-2) were invited to participate in the study. On entering the clinic, the women first had further mammography and were then interviewed by the study fieldworker, after which they were seen by the consultant. Information from the interview was taken before the women knew the results of the mammogram.

The interview obtained information on marital status, occupation, height, smoking, and alcohol intake and included a short (25 item) food frequency questionnaire. Weight, waist, and hip measurements were taken. As time at the interview was limited, a more detailed questionnaire on food intake was given to each subject to complete at home and return by post. This questionnaire, adapted from a previously validated food frequency questionnaire ${ }^{22} 23$ included 141 food and drink categories. Subjects could specify how much of these foods were usually eaten and how often they ate them over the last year. Allowance was made for summer and winter variations in consumption of vegetables and seasonal variation in fruit intake. Detail on types of fat used for cooking and spreading was obtained. The postal questionnaire included further questions on smoking, reproductive history, and views of the breast screening service. The longer dietary questionnaire was analysed using a specially adapted computer programme. ${ }^{24}$

Data were entered onto computer for all women requiring further clinical procedures; all women recalled to have an early rescreen; and a random sample of the women who were found to be normal and referred for a routine rescreening appointment (standard recall). Each week the number of women in the first two groups was counted and twice this number of normal women were randomly selected for analysis as the standard recall group. Subjects

Table 1 Nutrient intake (median (2.5 and 97.5 percentiles) for cases and controls including the National Diet and Nutrition Survey (NDNS) results for comparison)

\begin{tabular}{|c|c|c|c|c|c|}
\hline Nutrient & Case median & $\begin{array}{l}\text { Benign breast disease } \\
\text { median }\end{array}$ & Early rescreen median & Standard recall median & NDNS median \\
\hline Total energy (kcal) & $1642(728,3044)$ & $1612(774,3126)$ & $1645(900,3124)$ & $1611(790,2987)$ & $1620(810,2340)$ \\
\hline Protein $(\mathrm{g})$ & $75.4(40.5,127.4)$ & $75.0(35.0,131.0)$ & $75.0(40.0,131.6)$ & $75.0(37.0,133.4)$ & $62.9(33.7,91.8)$ \\
\hline Carbohydrate (g) & $197(73,399)$ & $207(91,443)$ & $206(91,436)$ & $198(87,390)$ & $178(84,285)$ \\
\hline Complex carbohydrate $(\mathrm{g})$ & $100(29,241)$ & $106(30,253)$ & $106(44,252)$ & $104(36,252)$ & 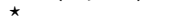 \\
\hline Sugars $(\mathrm{g})$ & $99(29,199)$ & $90(34,213)$ & $93(39,232)$ & $91(31,187)$ & $78(25,147)$ \\
\hline Total fat $(\mathrm{g})$ & $60.0(23.0,118.9)$ & $59.0(26.0,129.0)$ & $59.0(29.0,131.2)$ & $60.0(22.4,122.7)$ & $70.2(32.3,112.5)$ \\
\hline Monosaturated fat (g) & $23.0(8.0,49.0)$ & $23.0(9.0,51.5)$ & $24.0(10.0,48.2)$ & $24.0(8.0,49.4)$ & $20.5(10.1,35.5)$ \\
\hline Polyunsaturated fat (g) & $8.6(2.9,22.0)$ & $9.0(3.0,24.1)$ & $9.0(3.0,23.3)$ & $9.0(2.6,20.4)$ & $7.9+(2.9,20.0)$ \\
\hline Saturated fat (g) & $23.0(8.0,50.4)$ & $24.0(8.5,55.0)$ & $23.0(10.0,56.2)$ & $24.0(8.1,52.2)$ & $30.6(14.3,50.6)$ \\
\hline Alcohol (g) & $1(0.0,33.5)$ & $1(0.0,25.4)$ & $1(0.0,29.5)$ & $1.09(0.0,24.0)$ & $1.6^{\star}$ \\
\hline Fibre $(\mathrm{g})$ & $24.0(7.0,57.4)$ & $26.0(9.0,62.5)$ & $26.0(8.9,61.0)$ & $25(10.0,52.4)$ & $18.8(8.6,32.9)$ \\
\hline Cholesterol (mg) & $260(88,590)$ & $242(83,730)$ & $259(99,569)$ & $247(77,586)$ & $288(113,515)$ \\
\hline Vitamin C (mg) & $98.5(16.5,272.8)$ & $103.0(28.5,276.7)$ & $110.0(23.0,277.2)$ & $107.0(29.9,235.0)$ & $58.8 \ddagger(17.9,169)$ \\
\hline Vitamin E (mg) & $5.1(2.0,13.0)$ & $5.0(2.0,12.5)$ & $6.0(2.0,12.0)$ & $5.5(2.0,12.0)$ & $6.6 \ddagger(2.4,14.1)$ \\
\hline$\beta$ Carotene $(\mu \mathrm{g})$ & $3390(488,9466)$ & $3272(527,9778)$ & $3350(415,8804)$ & $3457(609,8384)$ & $1848(214,7121)$ \\
\hline Retinol $(\mu \mathrm{g})$ & $705(82,1702)$ & $690(44,3144)$ & $585(91,2967)$ & $672(76,2970)$ & $516 \neq(192,5487)$ \\
\hline Calcium (mg) & $833(304,1702)$ & $867(331,1819)$ & $864(303,1648)$ & $843(340,1741)$ & $731 \ddagger(305,1131)$ \\
\hline Iron (mg) & $12.0(5.0,29.0)$ & $13.0(4.7,31.4)$ & $13.0(5.0,30.2)$ & $12.7(6.0,28.4)$ & $10.1 \neq(5.6,12.1)$ \\
\hline Zinc (mg) & $10.0(4.5,22.0)$ & $10.0(4.9,21.5)$ & $11.0(5.0,19.0)$ & $10.0(5.0,20.0)$ & $8.3(4.5,13.7)$ \\
\hline
\end{tabular}

* Information not available. $†$ From n-6 polyunsaturated fatty acids only. $\ddagger$ From food sources only. 
Table 2 Results of logistic regression analysis comparing cases and standard recall groups

\begin{tabular}{|c|c|c|c|}
\hline Nutrient & Quartile & OR $(95 \% C I)^{*}$ & $\chi^{2}$ test for trend \\
\hline \multirow{4}{*}{ Saturated fat } & 1 & 1.00 & 0.10 \\
\hline & 2 & $2.46(1.43,4.24)$ & 0.10 \\
\hline & 3 & $1.79(0.93,3.46)$ & \\
\hline & 4 & $2.35(1.11,4.95)$ & \\
\hline \multirow[t]{4}{*}{ Monounsaturated fat } & 1 & 1.00 & 0.37 \\
\hline & 2 & $1.18(0.68,2.06)$ & \\
\hline & 3 & $0.69(0.36,1.32)$ & \\
\hline & 4 & $0.86(0.41,1.80)$ & \\
\hline \multirow[t]{4}{*}{ Polyunsaturated fat } & 1 & 1.00 & 0.15 \\
\hline & 2 & $0.95(0.55,1.63)$ & \\
\hline & 3 & $0.88(0.47,1.67)$ & \\
\hline & 4 & $0.61(0.30,1.26)$ & \\
\hline \multirow{4}{*}{ Protein } & 1 & 1.00 & 0.67 \\
\hline & 2 & $1.18(0.68,2.04)$ & \\
\hline & 3 & $1.30(0.69,2.43)$ & \\
\hline & 4 & $1.17(0.56,2.47)$ & \\
\hline \multirow[t]{4}{*}{ Complex carbohydrate } & 1 & 1.00 & 0.28 \\
\hline & 2 & $1.17(0.73,1.88)$ & \\
\hline & 3 & $0.84(0.48,1.45)$ & \\
\hline & 4 & $0.77(0.41,1.42)$ & \\
\hline \multirow{4}{*}{ Sugar } & 1 & 1.00 & 0.93 \\
\hline & 2 & $0.74(0.44,1.22)$ & \\
\hline & 3 & $1.53(0.93,2.53)$ & \\
\hline & 4 & $1.28(0.73,2.24)$ & \\
\hline \multirow[t]{4}{*}{ Alcohol } & 1 & 1.00 & 1.00 \\
\hline & 2 & $0.77(0.49,1.21)$ & \\
\hline & 3 & $0.97(0.63,1.49)$ & \\
\hline & 4 & $0.97(0.61,1.54)$ & \\
\hline \multirow[t]{4}{*}{ Iron } & 1 & 1.00 & 0.03 \\
\hline & 2 & $0.82(0.48,1.40)$ & \\
\hline & 3 & $0.51(0.26,0.99)$ & \\
\hline & 4 & $0.49(0.23,1.01)$ & \\
\hline \multirow[t]{4}{*}{ Vitamin E } & 1 & 1.00 & 0.10 \\
\hline & 2 & $1.42(0.79,2.55)$ & \\
\hline & 3 & $1.36(0.65,2.86)$ & \\
\hline & 4 & $2.05(0.93,4.56)$ & \\
\hline
\end{tabular}

^ OR adjusted for demographic and reproductive factors determined by previous modelling.

to be included in the analysis who had not returned the postal questionnaire after three weeks were sent a reminder letter and further questionnaire.

Women were followed up and those who were subsequently found to have breast cancer were analysed as cases. Three control groups were formed (a) women who were diagnosed with benign breast disease; (b) the early rescreen group and the standard recall group.

Over the data collection period some women in the early rescreen group returned for a repeat visit. These women were invited to participate again in the study to assess repeatability of the questionnaires. Repeat data were not included in this analysis.

DATA ANALYSIS

The data were analysed using Stata. ${ }^{25}$ Simple descriptive statistics were calculated for the demographic, reproductive, and diet related variables measured by the two questionnaires on the four groups: cases; benign breast disease; early rescreen; and standard recall. Subjects with missing nutritional information

Table 3 Ratio of energy intake (MF) to calculated basal metabolic rate for subjects

\begin{tabular}{llllll}
\hline & $\begin{array}{l}\text { Cases } \\
\text { cumulative } \\
\%\end{array}$ & $\begin{array}{l}\text { Benign breast } \\
\text { disease cumulative } \\
\%\end{array}$ & $\begin{array}{l}\text { Early rescreen } \\
\text { cumulative \% }\end{array}$ & $\begin{array}{l}\text { Standard } \\
\text { recall } \\
\text { cumulative \% }\end{array}$ & $\begin{array}{l}\text { NDNS study } \\
\text { cumulative \% }\end{array}$ \\
\hline Less than 1.0 & 32 & 33 & 30 & 33 & 26 \\
Less than 1.2 & 55 & 58 & 54 & 55 & 47 \\
Less than 1.4 & 75 & 73 & 75 & 75 & 71 \\
Less than 1.6 & 86 & 84 & 89 & 86 & 87 \\
All & 100 & 100 & 100 & 100 & 100 \\
Number & 196 & 166 & 326 & 763 & 1102 \\
Mean & 1.19 & 1.20 & 1.23 & 1.20 & 1.22 \\
Median & 1.15 & 1.13 & 1.17 & 1.16 & 1.23 \\
5th percentile & 0.61 & 0.64 & 0.70 & 0.63 & 0.83 \\
95th percentile & 1.88 & 1.93 & 2.06 & 1.93 & 1.93 \\
\hline
\end{tabular}

were compared with those with complete data using logistic regression to assess differences in disease status, demographic, and reproductive details. Completed values for each case and control group of subjects were compared with the UK National Diet and Nutrition Survey (NDNS). ${ }^{26}$

Unconditional logistic regression models were fitted to analyse the nutritional data for each control group. These were made up of three components: important demographic and reproductive factors determined from previous modelling ${ }^{21}$ (age group at screening, age at menarche, age at first birth, social class, body mass index, and smoking); components of calorie intake (alcohol, complex carbohydrates, protein, polyunsaturated fat, monounsaturated fat, saturated fat, cholesterol, and sugar); and non-calorific nutrients ( $\beta$ carotene, calcium, fibre, iron, retinol, vitamin $\mathrm{C}$, vitamin $\mathrm{E}$, and zinc). Full models, including all three components, were fitted using quartiles of nutrient values. As this study was primarily concerned with dietary fat, non-calorific nutrients were eliminated from reported models unless at least one quartile attained a statistical significance of $10 \%$. From the final model, an estimate of the odds ratio and $95 \%$ confidence intervals were calculated for each quartile of nutrients remaining in the model. Evidence of a linear trend in the odds ratios for quartiles of each nutrient was also tested.

To assess possible under-reporting, estimated basal metabolic rates were calculated from anthropometric data ${ }^{27}$ and compared with self reported dietary intakes of energy.

\section{Results}

Interviews were carried out on 1947 women (98\% response) in Southampton and 1280 women (96\% response) in Portsmouth. From this number, 1813 subjects were chosen for further study. ${ }^{21}$ Of these, 87\% (1577) returned the postal questionnaire with usable dietary information. We found no evidence that the 236 women with missing nutrient values had different distributions of the demographic and reproductive characteristics, nor of disease status, though they were more likely to have missing reproductive data.

The 1577 subjects consisted of 220 women with breast cancer (cases); 179 women with benign breast disease; 353 women called back for an early rescreen and 825 who were given a standard recall appointment.

Summary statistics for nutritional intake (table 1) are given in a format comparable to that given by the NDNS report. ${ }^{26}$ Few differences in nutritional intake were apparent between the four groups in this study. Although subjects had a similar intake of calories to the NDNS, a smaller percentage of total energy came from fat intake. Our subjects also had higher intakes of most vitamins and minerals measured.

Adjusted odds ratios and 95\% confidence intervals are shown for the logistic regression model comparing dietary intake for cases with that of the standard recall controls only (table 2 ), as results from other comparison groups 
were not materially different. The only noncalorific nutrients remaining in the model after exclusions were iron and vitamin E. Subjects with iron intakes above the median value were at half the odds of those with intakes below the median. Subjects with vitamin $\mathrm{E}$ intake above the reference category had increased odds with some slight evidence of linear trend $(p=0.10)$. For fat intake, the odds decreased with increasing polyunsaturated fat $(p=0.15)$, showed no trend with monounsaturated fat $(p=0.37)$, and were increased with increased saturated fat, although no trend was apparent $(p=0.10)$. No pattern was clear for other calorie providing nutrients. Comparisons were made between the cases and the other control groups and similar results were found.

The ratio of energy intake (MJ) to the calculated basal metabolic rate for those subjects with recorded height and weight is shown for the four groups separately (table 3). Little difference was apparent between the groups. A higher proportion of subjects in this study than in the NDNS had low ratios indicating possible under-reporting.

\section{Discussion}

The response rate to this study was high. Of those interviewed who were to be analysed, $87 \%$ returned the postal questionnaire with usable dietary information.

The method chosen to assess dietary intake was a food frequency questionnaire (FFQ). This method asks subjects to describe their usual intake of foods rather than measuring actual intake. When carefully designed, FFQs have been shown to provide valid and repeatable measures of nutrient intake. ${ }^{28}$ The FFQ used in this study had been previously validated in an Australian population, ${ }^{22}{ }^{23}$ it was then piloted and adapted for use in our study population.

The FFQ is the most appropriate dietary assessment method for large scale epidemiological studies. It can be completed by the study subjects and does not entail complicated weighing or recording procedures, which can lead to changes in diet or under-reporting of actual foods consumed. ${ }^{29}$ Measures of diet that do not rely on subjects recording intake in some way entail invasive blood tests. Reliable biological markers for all nutrients consumed are still not available. FFQs have been shown to give results which correlate significantly with some blood measures including carotene and $\alpha$ tocopherol. ${ }^{30}$

The FFQ relies on memory for recall of usual consumption of food items. It is probable that subject's memories are equally unreliable across all groups, resulting in a dilution of any effect of different dietary intake between groups rather than bias in one direction or another. Recall bias can occur in case-control studies, because recall of diet before the disease onset will be biased towards current dietary intake, which may be different, having changed as a result of the disease. ${ }^{12}{ }^{13}$ This study aimed to limit this bias by using subjects from the screening programme. This gave two main advantages over other case-control studies: subjects would
KEY POINTS

- This study design aimed to reduce recall bias associated with dietary recall in case-control studies.

- No statistically significant trends in fat intake were found between cases and controls.

- Iron intake was consistently protective across all three control groups compared with cases.

be at an early stage of disease, possibly before any dietary changes resulting from the disease; and the interviews took place at a time before the subjects knew their diagnosis.

The results showed no statistically significant trends in nutrient intake between the cases and the control groups for fat intake. This is in agreement with most recently published results from cohort studies. ${ }^{915} 3132$ There was a suggestion from our study that risk may increase with increased saturated fat intake. The only cohort study that has shown an effect of a high fat diet was the NHANES study, which suggested a protective effect of total fat and saturated fat on breast cancer. ${ }^{33}$ However, the authors acknowledge methodological problems with the dietary assessment and this study scored poorly in a review of published studies. ${ }^{9}$ The same review looked at 35 case-control studies, of these 14 presented odds ratios for estimates of total fat intake. Most of these studies tended to suggest an increased risk of breast cancer with higher fat intake, though only two were statistically significant. One study suggested a protective effect of a higher fat diet. ${ }^{10}$ Another review of 12 case-control studies that had carried out a combined analysis, showed a statistically significant positive association between breast cancer risk and saturated fat intake in postmenopausal women. ${ }^{11}$ We believe that the principal reason our case-control study contradicted these is that recall bias was reduced in our study. A case-control study carried out in Sweden also using subjects from a mammography screening programme did not find any increased risk with high fat intake. ${ }^{34}$ Polyunsaturated fatty acid (PUFA) intake showed a non-significant protective effect for all three case-control comparisons. Most case-control studies have not shown any significant effect of PUFA on breast cancer risk $^{11}$ although one study in Singapore has shown a significant protective effect of PUFA. ${ }^{35}$ Cohort studies have also not shown any effect of PUFA on breast cancer risk. Polyunsaturated fat has been suggested to be a promoter of breast cancer, but in particular it is the $n-6$ series of fats, which are derived from vegetable oils that seems to have this effect. On the other hand, PUFA from the n-3 series derived from fish oils may inhibit tumour development. ${ }^{36}$

The nutrient intakes for our sample show differences to dietary intake from the National Diet and Nutrition Survey (NDNS) ${ }^{26}$ (table 1). NDNS used a seven day weighed intake to assess dietary intake, recording actual rather 
than usual intake. In the NDNS, median total energy intake for women aged 50-64 years was $1620 \mathrm{kcal}$, this result was similar to our survey. It is known that weighed intakes lead to underreporting and the NDNS found that $47 \%$ of women surveyed had an energy intake to basal metabolic rate ratio of less than 1.2. Habitual intakes of this order are unlikely to meet requirements, suggesting that under-reporting in the national study had occurred. ${ }^{26}$ In our study about $55 \%$ of the women had energy intake to basal metabolic rate ratios of less than 1.2. However, our study had higher intakes of protein, $\mathrm{CHO}$, sugars, fibre, vitamin $\mathrm{C}$, carotene, calcium, iron, and zinc than the NDNS suggesting that under-reporting for all nutrients was not a problem. Reported fat intakes were lower in our study. In particular saturated fat intake was lower in our study. It is possible that the FFQ used here was underestimating fat, particularly saturated fat intake. As fat was the focus of the study, however, it would be more likely that the FFQ would overestimate intakes. It is also possible that the women in our study were eating a lower fat diet than was found by the NDNS. The fieldwork for the NDNS was carried out in 1986-87. Since then health promotion has been emphasising reducing fat in the diet and more low fat products are available. There is some evidence that absolute fat intakes have been decreasing over the past decade. ${ }^{37}$ Further work is needed to compare the food sources of nutrients in diets from our sample with NDNS results.

Vitamin C intakes were particularly high in our study. This may reflect the comparatively affluent nature of the population being studied because vitamin $\mathrm{C}$ intake and social class are positively correlated..$^{38}$ Fibre intakes were also high. The subjects in our study may have been health conscious and eaten a healthier diet than the majority of the population. ${ }^{26}$ They had already indicated their interest in health issues by attending the screening clinic.

Iron intake showed a consistently protective effect across all three control groups when compared with cases. Only two epidemiological studies have reported iron intake in relation to breast cancer, ${ }^{39} 40$ although neither of these found statistically significant associations. Iron intakes in our study were $2-3 \mathrm{mg}$ higher on average than those found for women of similar age in the NDNS. ${ }^{26}$ Iron in the diet comes mainly from cereals, meat, and vegetables. In an ecological study there was a highly negative correlation of cereal intake with breast cancer mortality in England and Wales over a 50 year period. ${ }^{41}$ Epidemiological studies have shown that people with high body stores of iron are at increased risk for cancer and animal studies have shown that tumour cells need iron to grow. ${ }^{42}$ The results of our study do not support these findings. This study only measured dietary intake of iron from food, however, and took no account of iron supplement use. Supplementary iron has been shown to provide $15 \%$ of women's average intake from all sources. ${ }^{26}$

There was a suggestion from these data that vitamin $\mathrm{E}$ intake increased odds of breast cancer, although the test for trend was not signifi- cant. Vitamin $\mathrm{E}$ is generally thought to have a protective effect. It functions as an antioxidant, particularly in cell membranes where it plays a part in protecting the body from lipid-peroxide generated damage; it also inhibits the formation of carcinogenic nitrosamines and nitrosamides. ${ }^{43} \mathrm{~A}$ review of five case-control studies that looked at dietary intake of vitamin $\mathrm{E}$ and breast cancer found that three studies showed a protective effect for vitamin $\mathrm{E}$ while the other two did not. ${ }^{43}$

In line with recent cohort studies, this study has shown no evidence to support the hypothesis that dietary fat is an important contributor to breast cancer rates. It is unlikely that dietary fat intake has an important influence on breast cancer risk, unless this influence occurs much earlier in life.

The authors would like to thank Pauline Herd, Cymmone Imms, and Christine Candy for fieldwork and Kirsten Maters for data entry. Funding: the research was supported by: Wessex Cancer Trust,
Wessex Medical School Trust, Wessex Regional Health AuthorWessex Medical School Trust, Wessex R
ity, Parke-Davis Research Laboratories. Conflicts of interest: none.

1 Kelsey JL. Breast cancer epidemiology: summary and future directions. Epidemiol Rev 1993;15:256-63.

2 Seidman H, Stellman SD, Mushinski MH. A different perspective on breast cancer risk factors: some implications of the non-attributable risk. New York: American Cancer Society Professional Education Publication, 1983.

3 Tannenbaum A. The genesis and growth of tumors III. Effects of a high-fat diet. Cancer 1942;2:468-75.

4 Freedman LS. Meta-analysis of animal experiments on dietary fat intake and mammary tumours. Stat Med dietary fat intake

5 Armstrong B, Doll R. Environmental factors and cancer ncidence and mortality in different countries with special reference to dietary practices. Int $\mathcal{F}$ Cancer $1975 ; 15: 617-31$.

6 Ingram DM. Trends in diet and breast cancer mortality in England and Wales 1928-77. Nutr Cancer 1981;3:75-80.

7 Rohan TE, Bain CJ. Diet in the etiology of breast cancer. Epidemiol Rev 1987;9:120-45.

8 Dunn JE. Cancer epidemiology in populations of the United States - with emphasis on Hawaii and California and Japan. Cancer Res 1975;35:3240-5.

9 UK Nutritional Epidemiology Group. Diet and cancer. London:The Nutrition Society, 1993.

10 van't Veer P, Kok FJ, Brants HAM, Ockhuizen T, Sturmans $\mathrm{F}$, Hermus RJJ. Dietary fat and the risk of breast cancer. Int F Epidemiol 1990;19:12-18.

11 Howe GR, Hirohata T, Hislop G, et al. Dietary factors and risk of breast cancer: combined analysis of 12 case-control risk of breast cancer: combined analysis of
studies. F Natl Cancer Inst 1990;82:561-9.

12 Giovannucci E, Stampfer MJ, Colditz GA, et al. A comparison of prospective and retrospective assessments of diet in th study of breast cancer. Am F Epidemiol 1993;137:502-11.

13 Friedenreich CM, Howe GR, Miller AB. The effect of recall bias on the association of calorie providing nutrients and breast cancer. Epidemiology 1991;2:424-9.

14 Wynder EL, Stellman SD. The "over-exposed" control group. Am f Epidemiol 1992;135:459-61.

15 Hunter DJ, Spiegelman D, Adami HO, et al. Cohort studies of fat intake and the risk of breast cancer - a pooled analysis. N Engl f Med 1996;334:356-61.

16 Garland M, Willett WC, Manson JE, Hunter DJ. Antioxidant micronutrients and breast cancer. $f$ Am Coll Nutr 1993;12:400-11.

17 Holmberg L, Ohlander EM, Byers T, et al. Diet and breast cancer risk. Arch Intern Med 1994;154:1805-11.

18 Hunter DJ, Manson JE, Colditz GA, et al. A prospective study of the intake of vitamins $\mathrm{C}, \mathrm{E}$ and $\mathrm{A}$ and the risk of breast cancer. N Engl f Med 1993;329:234-40.

19 Friedenreich CM, Howe GR, Miller AB. Recall bias in the association of micronutrient intake and breast cancer. $\mathcal{F}$ Clin Epidemiol 1993;46:1009-17.

20 Hunter DJ, Willett WC. Diet, body size and breast cancer. Epidemiol Rev 1993;15:110-32.

21 Thomas E, Cade J, Vail A. Risk factor analysis of data from assessment clinics in the UK breast screening programme: a case-control study in Portsmouth and Southampton. $\mathcal{F}$ Epidemiol Community Health 1996;50:144-8.

22 Rohan TE, Potter JD. Retrospective assessment of dietary intake. Am 7 Epidemiol 1984;120:876-87.

23 Rohan TE, Record SJ, Cook MG. Repeatability of estimates of nutrient and energy intake: the quantitative food of nutrient and energy intake: the quantitat
frequency approach. Nutr Res 1987;7:125-37.

24 Record S, Baghurst K. Dietary assessment by computer. Adelaide:CSIRO Human Nutrition, 1990. 
25 StataCorp. Stata Statistical Software:Release 4.0. College Station, TX:Stata Corporation, 1995.

26 Gregory J, Foster K, Tyler H, Wisemann M. The dietary and nutritional survey of British adults. London: HMSO, 1990.

27 World Health Organisation. Energy and protein requirements. Report of a joint $\mathrm{FAO} / \mathrm{WHO} / \mathrm{UNU}$ expert consultation. Technical Rpt Series 724. Geneva:WHO, 1985.

28 Willett WC, Sampson L, Stampfer MJ, et al. Reproducibility and validity of a semiquantitative food frequency questionnaire. Am $\mathcal{F}$ Epidemiol 1985;122:51-65.

29 Pryer J, Brunner E, Elliott P, Nichols R, Dimond H, Marmot M. Who complied with COMA 1984 dietary fat recommendations among a nationally representative sample of British adults in 1986-7 and what did they eat? Eur $\mathcal{F}$ Clin Nutr 1995;49:718-28.

30 Willett WC, Stampfer MJ, Underwood BA, Speizer FE Rosner B, Hennekens $\mathrm{CH}$. Validation of a dietary questionnaire with plasma carotenoid and $\alpha$ - tocopherol questionnaire with plasma carotenoid

31 Willett WC, Stampfer MJ, Colditz GA, Rosner BA Hennekens CH, Speizer FE. Dietary fat and risk of breast Hennekens CH, Speizer FE. Dietary
cancer. N Engl f Med 1987;316:22-8.

32 Graham S, Zielezny M, Marshall J, et al. Diet in the epidemiology of post menopausal breast cancer in New York state cohort. Am f Epidemiol 1992;136:1327-37.

33 Jones DY, Schatzkin A, Green SB, et al. Dietary fat and breast cancer in the National Health and Nutrition Examination Survey I epidemiologic follow up study. F Natl Cancer Inst 1987;79:465-71.
34 Holmberg L, Ohlander EM, Byers T, et al. Diet and breast cancer risk. Arch Intern Med 1994;154:1805-11.

35 Lee HP, Gourley L, Duffy SW, Esteve J, Lee J, Day NE. Dietary effects on breast-cancer risk in Singapore. Lancet 1991;337:1197-200.

36 Sanders T. Dietary fats. London: Health Education Authority, 1994.

37 Ministry of Agriculture, Fisheries and Food. National food survey:household food consumption in 1993. London: HMSO, 1994.

38 Cade JE, Barker DJP, Margetts BM, Morris JA. Diet and nequalities in health in three English towns. BMf 1988;296:1359-62.

39 Boing H, Martinez L, Frentzel-Betme R, Oltersdorf U. Regional nutritional pattern and cancer mortality in the Federal Republic of Germany. Nutr Cancer 1985;7:121-30.

40 Chen J, Geissler C, Parpia B, Li J, Campbell TC. Antioxidant status and cancer mortality in China. Int $\mathcal{f}$ Epidemiol 1992;21:625-35.

41 Ingram DM. Trends in diet and breast cancer mortality in England and Wales 1928-1977. Nutr Cancer 198;3:75-80.

42 Jacobs M, ed. Diet and cancer:m Markers, prevention and treatment. Advances in experimental medicine and biology, vol 354. New York:Plenum Press, 1994.

43 Garland M, Willett WC, Manson JE, Hunter DJ. Antioxidant micronutrients and breast cancer. F Am Coll Nutr 1993;12:400-11. 